\title{
Helping families toward the goal of self-support: Montana's EDUFAIM program
}

\author{
Stephen F. Duncan \\ Brigham Young University - Provo, sduncan@byu.edu \\ Tim Dunnagan \\ Suzanne Christopher \\ Lynn Paul
}

Follow this and additional works at: https://scholarsarchive.byu.edu/facpub

Part of the Social and Behavioral Sciences Commons

\section{Original Publication Citation}

Duncan, S. F., Dunnagan, T., Christopher, S., \& Paul, L. (2003). Helping families toward the goal of self-support: Montana's EDUFAIM program. Families in Society, 84, 213-222.

\section{BYU ScholarsArchive Citation}

Duncan, Stephen F.; Dunnagan, Tim; Christopher, Suzanne; and Paul, Lynn, "Helping families toward the goal of self-support: Montana's EDUFAIM program" (2021). Faculty Publications. 4856.

https://scholarsarchive.byu.edu/facpub/4856

This Peer-Reviewed Article is brought to you for free and open access by BYU ScholarsArchive. It has been accepted for inclusion in Faculty Publications by an authorized administrator of BYU ScholarsArchive. For more information, please contact ellen_amatangelo@byu.edu. 


\title{
Helping Families Toward the Goal of Self-Support: Montana's EDUFAIM Program
}

\author{
Stephen F. Duncan, Tim Dunnagan, Suzanne Christopher, \& Lynn Paul
}

\begin{abstract}
This article on a self-reliance education program describes the development, implementation, and elements of success of Educating Families to Achieve Independence in Montana (EDUFAIM) as a model for statewide integration of efforts to help families dependent on public assistance move toward a more self-supporting lifestyle. An overview of the EDUFAIM program, from its beginnings to implementation strategies, open the article, followed by a discussion of the evidence of EDUFAIM's success, including effective collaboration, effective educational materials and teaching strategies, effective evaluation strategies, and effective use of evaluation data. The article concludes with a discussion of program limitations.
\end{abstract}

MONTANA IS AMONG THE LAST of the truly frontier states. Comprising of 147,138 square miles, it is the fourth largest state. At a population of nearly 883,000 (U.S. Census, 1999), it has one of the lowest population densitics ( 6 persons per square mile) in the nation. Of the state's 56 counties, 23 are "frontier" counties, meaning they contain fewer than 2 persons per square mile. Seven more counties contain between 2 and 3 persons per square mile. Bchind Alaska and Wyoming, Montana ranks as the third most sparsely populated state. Consequently, implementing programs to strengthen limited resource families in such a vast, populated area of the nation presents special challenges.

In 1994, Montana became one of the first states to reform welfare by creating the Families Achieving Independence in Montana (FAIM) program. A program assumption was that families coming off welfare often need life skills education that supports the goals of cconomic selfsupport. Working in partnership with the Montana Department of Public Health and Human Services (DPHHS), the Montana State University Extension Service developed: Educating Families to Achieve Independence in Montana (EDUFAIM).

The article describes the development, implementation, and elements of EDUFAIM's success as a model for statewide integration of efforts to help families dependent on public assistance move toward a more self-supporting lifestyle. First, we provide a program overview. Next, we discuss the evidence of EDUFAIM's success, including effective collaboration, effective educational materials and teaching strategies, effective evaluation strategies, and effective use of evaluation data. We conclude with a discussion of program limitations.

\section{Theoretical Framework}

EDUFAIM is based on principles of empowerment (Cochran \& Woolever, 1983). Empowerment theory implies "that individuals and families have strengths that can be mobilized, and that they have some idea of what their goals ought to be and what they need to do to achieve them" (Lee \& Goddard, 1989, p. 303). Even if they are not functioning well, this perspective holds that individuals and families can develop the necessary skills and strengths they need to have the quality of life they want. One criticism of empowerment theory as it is applied in U.S. culture is that it overemphasizes individual responsibility for change at the expense of societal factors (Minkler, 1997).

To address this concern, EDUFAIM program development was also guided by an understanding of the complex needs of limited resource families. Program offerings are ticd

Families in Society: The Journal of Contemporary Human Services Copyright 2003 Alliance for Children and Families 
to participant needs and reflect a comprehensive, interdisciplinary approach to helping individuals and families function effectively in the community context (Cooperative Extension System [CES], 1991). From a human ecological perspective, there are limiting factors at different levels of the social ecology that impede individuals' and families' access to basic resources (McCray \& Williams-Willis, 1991, cited in CES, 1991. Factors occur at the individual/houschold level, the community services level, and the community characteristics level. EDUFAIM efforts focus at the individual/ household level, helping program participants acquire the knowledge and skills needed for self-support. Families receiving public assistance have insufficient earnings for adequate health care, adequate nutrition, quality child care, and adequate housing. They may lack personal resources for managing stress, getting and keeping jobs, and parenting effectively. These families may require skills in managing limited finances and family responsibilities. Families with enhanced personal and family resources become more active contributors to their community, enhancing its characteristics.

We were also guided by transformative learning theory in structuring educational processes designed to promote selfsupporting lifestyles (see Christopher, Dunnagan, Duncan, \& Paul, $200 \mathrm{l}$ (a). Transformative learning theory is based on the assumption that a learner's current perspective and consequent approach to life derives from their experiences, thoughts, values, and insights (Taylor, 1997). Transformative learning can assist learners to assess their current perspectives and approaches to life and provide an opportunity to change perspectives, thereby allowing for behavior change.

Outcomes seen within a transformative learning environment include: (a) an empowered sense of self and an increase in self-confidence in new roles and relationships, (b) fundamental changes in the way learners see themselves and their life assumptions, (c) more functional strategies and resources for taking action and gaining control over their lives, (d) compassion for others, and (e) new connectedness with othcrs (Courtenay, Merriam, \& Reeves, 1998; Taylor, 1997).

Transformative learning can be fostered by including: (a) teachers who are empathetic, caring, authentic, sincere and who demonstrate a high degrec of integrity, (b) learning conditions that promote a sense of safety, openness, and trust, and (c) instructional methods that support a learnercentered approach that promotes student autonomy, participation, reflection, and collaboration (Robertson, 1996).

\section{EDUFAIM: The Program}

FAIM, Montana's welfarc program, has three components: the Job Supplement Program, the Pathways Program, and the Community Services Program. EDUFAIM is offered through the Pathways Program, which is designed to provide families with educational opportunities leading to permanent public assistance alternatives. Non-FAIM at-risk families are referred to EDUFAIM classes by collaborators.

EDUFAIM is designed to help limited resource families gain the knowledge, attitudes, and skills needed for effective family resource management and progress toward a self-supporting lifestyle. Specific educational program content is determined by the needs identified and prioritized by individual families and communities. Program areas may include, but are not limited to, nutrition and health (e.g., preventive health cducation, maternal and infant nutrition, food preparation, healthy and low-cost food shopping and food safety), individual and family development (e.g., parent cducation, building family strengths, balancing work and family, building self-efficacy and positive expectations, managing stress), resource management (e.g., time management, moncy management, consumer skills), community development (e.g., small business development), and housing (e.g., housing affordability and availability, protection of housing investment, health-related cnvironmental issues within the home).

Upon entering the Pathways program, families develop a Family Investment Agreement (FIA) in consultation with a FAIM coordinator. FIA's list the kinds of EDUFAIM courses families believe they need to help them move toward greater self-sufficiency. Classes are taught in small group settings or one-on-one, as needed, by local EDUFAIM staff consisting of an EDUFAIM Family Educator assisted by an EDUFAIM Program Aide. The Family Educator is a master's degree holding professional with considerable experience working with limited resource families. Program Aides are paraprofessionals indigenous to the limited resource population who have real-life experience on public assistance. This combination of professional and real-life experience is likely to form the basis of strong, empathetic, and caring associations between educators and participants (Giblin, 1989). The Family Educator and Program Aide work collaboratively with the local Community Advisory Council for FAIM, consisting of agency representatives, volunteers, and members of the target audience.

Local staff are supported with educational materials and training, evaluation, and computer technology by the state EDUFAIM Team. This team is comprised of resident and Extension faculty representing ten disciplines-family science, nutrition, adult development, adult education, child development, family economics, community development, housing, youth development, and computer technology. Each site has two computers, one for office use and one for public use. These computers provide Internet connectivity, allowing access to many web-based resources for their clientele and the ability to stay connected with other professionals locally and nationally. Specialists assist sites by pointing community EDUFAIM staff to resources that help support them in their work with limited resource audiences.

The state EDUFAIM team is in turn supported by college deans, department heads, Extension administration, and state directors of the DPHHS who have developed a 
shared vision and strategic plan for addressing the educational needs of at-risk families in Montana, using EDUFAIM as a vehicle. The vision of the EDUFAIM program is

\section{Supportive Montana communities that empower families to develop skills, knowledge and competencies necessary for managing family resources and progressing toward a self-supporting lifestyle.}

In connection with this vision, the EDUFAIM mission statement reads

\section{EDUFAIM is a collaborative effort of the Montana State University Extension Service, Department of Public Health and Human Services, and Community Advisory Councils that provides educational programs to empower FAIM and other at-risk fomilies in attaining knowledge and developing skills necessary for managing family resources and progressing toward a self-supporting lifestyle.}

This vision and mission statement form the basis of a comprehensive strategic plan for its accomplishment. The vision, mission, and strategic plan are reviewed and updated annually and course corrections are made when needed.

In turn, local EDUFAIM staff, and community advisory councils, have developed their own vision, mission, and strategic plan that is in line with the statc vision. They likewise hold regular meetings to revicw and update their plans.

Many life skills programs have been developed that share similarities with EDUFAIM (for a review of several programs, see Day, 1994; Kirby, 1996). However, many of these programs lack explicit theoretical bases to guide program development and educational processes. In addition, programs often are not tailored to the expressed needs of family members, and systematic evaluation data is lacking (Day, 1994). Many welfare-to-work programs focusing on cmployment have also been implemented, with positive benefits (Friedlander \& Burtless, 1994; Gueron, 1987; as cited in Kirby, 1996). These programs, however, lack a comprehensive focus on the complex needs of limited resource families, noted earlier. EDUFAIM is designed to overcome these gaps in program development, implementation, and evaluation.

\section{Birth of the EDUFAIM Collaboration}

In early 1995, specialists at Montana State University Extension Service met with DPHHS public assistance directors to discuss working together for limited resource families. Initial meetings focused on nutrition education and food resource management, since most of the state dollars available at that time for the education of limited resource families were earmarked for nutrition programs. However, it was clear that Montana families coming off public assistance needed more than nutrition education to make a successful transition to self-sufficiency.

For example, the advent of welfare reform changed welfare expectancies from a cash grant/entitlement orientation to a work requirement orientation. We concluded that many public assistance families now needed educational aid in a number of areas as they made the transition from welfare dependence to self-sufficiency. Grants were sought that would fund such a transition program in Montana. The first author applied for and received a State Strengthening grant from the Children, Youth, and Families at Risk Initiative (CYFAR) of the Cooperative State Research, Education, and Extension Service (CSREES). The state-level partnership had been forged.

While state-level partnership is important, without local collaboration and buy-in, the program would falter. The next step was to select local community sites. We contacted county extension agents and their county welfare directors to assess the level of interest and community buy-in to EDUFAIM. To be selected, sites needed to demonstrate interest and buy-in, and have a community infrastructure that would allow for the collaboration of many agencies to carry out the work. Additionally, in an attempt to reach the most resource-poor areas of the state, the percentage of children living in poverty at the selected sites needed to meet or exceed $20 \%$. Two sites were selected initially, serving five rural Montana counties.

\section{Elements of Program Success}

Several elements of program implementation have combined to make EDUFAIM a successful program, one that has been sustained by local revenues and expanded to reach a larger limited resource family audience. These elements include effective collaboration, effective educational materials and teaching strategies, effective evaluation strategies, and effective use of evaluation data. These elements are discussed below.

\section{Effective Collaboration}

The federal liaison external to EDUFAIM has termed it a "model of collaboration." One indicator of a successful col laboration is when collaborators give unsolicited praise for the program. After intervicws with collaborators, the federal liaison wrote that "agencies and local officials are able to articulate the positive changes that EDUFAIM is having on connecting users to appropriate services and education. It was noted many times that the educational component was what the state's FAIM effort lacked. Using a collaborative approach, they arc able to see real progress in the targeted population. Scveral of the agency leaders noted that other communities that they served were interested in the EDUFAIM model" (Woods, 1998).

Several specific collaboration strategies have been used with success in EDUFAIM; five are listed: 
Shared vision. From the outset, in participating communities, EDUFAIM has been viewed as the catalyst to coordinate the variety of necessary programs to help remove barriers to employment and help families to be self-supporting. Everyone at the table shared the vision that this collaboration would produce superior results.

Focus on participants' needs. The collaboration has been working in part because everyone has strived to keep in mind that collaboration exists to meet participant needs in the most effective way possible. Participants were interviewed during the design phase of EDUFAIM to learn from them what they needed to become self-reliant. Their responses, plus their representation as members of community advisory councils, helped form EDUFAIM's entire structure, service delivery approach, and strategic plan.

Use of most knowledgeable and experienced resources. We utilized the most knowledgeable and experienced resources in the community. Each of the participating organizations and agencies at the local level selected a top member of their team to guarantec a horizontal collaboration among "equals." This was done because it has been our experience that hierarchical collaborations do not work.

Because of this egalitarian arrangement, we have been able to recognize and respect our limitations and defer to the core competencies of other collaborators. As a result, EDUFAIM staff participate in an extremely strong referral network.

Compensation arrangements discussed in advance. Issues of ownership were discussed openly. At one site, ownership issues started to become a concern when Welfare-to-Work monies became available and there was the potential for interagency competition. However, because of the shared vision and focus on the needs of individuals, community agencies were able to come together to write the grant, and all compensation arrangements were completely and satisfactorily resolved.

Responsiveness to clientele. We discovered throughout the growth of our program that we needed to respond quickly to the needs of clientele and be as flexible in providing services as possible. It was essential to our success that our working cnvironment was responsive and the communication paths streamlined. Modern technology (i.e., e-mail, faxing, cell phone) helped us to perform optimally with our collaborators and participants.

\section{Effective Educational Materials and Teaching Strategies}

Care was taken to ensure that the programs sclected for EDUFAIM program areas were the best that could be found to meet educational needs. Prior to the beginning of EDUFAIM, a nationwide search was conducted to identify model programs in EDUFAIM's targeted areas. Many of the programs listed in the Appendix are those identified by field practitioners around the nation as being useful for addressing limited resource family educational needs. Others on this list were added as the program cvolved and materials were tested with additional familics. Since a "one-size-fits-all" approach to helping these families is doomed to failure, these programs and materials were adapted by the local EDUFAIM family educators to meet their needs. While core programs formed the basis of the EDUFAIM program, they were supplemented by other materials as needed.

Several learner-centered educational strategies guided by transformative learning theory were used by EDUFAIM family educators and program aides to accomplish educational objectives:

- Classes were offered in small groups or one-on-one, as needed, allowing for more individualized attention and for materials to be more effectively adapted to individual participant needs.

- At the beginning of EDUFAIM, educators assessed participants' adult basic education level. This enabled the educators to work with participants from where they were and adjust materials accordingly. It is important for educators to be sensitive to the fact that many participants may not have had positive educational experiences.

- Educators kept the material simple and to the point because of the vast differences in participant educational levels. Materials must relate to very basic life skills levels. Written material needed to be written at a low reading level or be simple enough that they can be easily adapted and interpreted.

- Many methods were chosen because of their effectiveness with visual and auditory learners, as is the case with many EDUFAIM participants. Specific approaches included hands-on activitics, vidco taping, group activities, group games, role playing, and narrative.

- Follow-through experiences were also part of the educational approach. Specifically, participants were encouraged to help each other learn during EDUFAIM classes and outside of class as an informal support group.

In EDUFAIM, participants choose the cducational offerings they believe they need to move toward a more self-supporting lifestyle. Once EDUFAIM courses are selected, however, participants must attend the classes or face sanctions from the state welfare agency. Such a policy presents a challenge to EDUFAIM instructors who are striving to create the warm, caring atmosphere needed for transformative learning. To help neutralize the effects of the threat of sanctions, EDUFAIM instructors relate with participants in ways that foster openness and trust. For instance, instructors openly acknowledge at the beginning of a course that they know some of the participants do not want to be there and emphasize the positive outcomes participants are likely to gain from full participation. Outside of class, EDUFAIM instructors encourage participants to drop by the EDUFAIM office to talk, use the Internet, or address other needs. 


\section{Effective Evaluation Strategies}

There were five evaluation objectives for EDUFAIM. The evaluation objectives related to changes in knowledge, skills, behaviors, and health orientation that promote self-sufficient living in a cost effective manner. The objectives included measuring (a) client empowerment for obtaining employment, (b) changes in mental health/ well-being, (c) changes associated with participation in core EDUFAIM classes, (d) transformative learning, and (e) cost containment associated with welfare programming (Dunnagan, Duncan, \& Paul, 2000). In this paper, we report the results for objectives a, b, d, and c.

Four measures were used to evaluate client empowerment for employment which included motivation, cognition, locus of control, and self-efficacy. These measures were included because of their relationship with empowerment (Zimmerman, 1990) and obtaining employment (Vinokur \& Caplin, 1987). The mental health/well-being measures evaluated levels of self-esteem, global life satisfaction, positive and negative affect, anxiety, and depression. These variables were selected because of their positive association with healthy relationships/families, positive social networks, and employment status. All of these measures demonstrated suitable reliability and validity. Importantly, the tools selected were also appropriate for the lower levels of literacy anticipated in this population (for a full description of these measures and sources, see Dunnagan et al., 2000).

Starting the second year of the EDUFAIM programming, data were collected on client empowerment and mental health/life satisfaction when clients entered the program (pretest) and three months after entrance into the program (posttest). During the data collection process, the evaluators experienced difficulty obtaining complete pretest and posttest data. During the second year of evaluation, complete pretest data were collected on 89 participants. However, complete posttest data were collected on only $38 \%(n=34)$ of participants.

Attrition was caused by factors including client employment, relocation, resistance to completing the survey, inability to contact participants for their post-test evaluation, and drop out. A number of actions were initiated to address the high attrition rates. First, cash incentives were made available to clients who completed the pretest and posttest survey. Second, EDUFAIM staff and research staff were more vigilant with data collection. Because of these efforts, at the end of four years, complete pre- and posttest data were collected on approximately $70 \%(n=162)$ of the 234 participants. Analyses of personal and demographic differences between participants who completed the pretest and posttest survey, and those who only completed the pretest survey showed that the two groups were not significantly different.

Empowerment for employment. The results of the survey data collection from 1997-2000 on measures of empow- erment and mental health are shown in Tables 1 and 2 respectively. The only statistically significant $(p<.05)$ measures related to empowerment were job-seeking efficacy and perceived job-seeking efforts. Consequently, over the 4-year period there was a significant increase in the participants' perceived ability to find a job and efforts put forth in this endeavor. However, the other nine areas related to participant empowerment did not show statistically significant changes.

Mental health. Mental health changes were more profound. Specifically, the direction of change for all of the mental health variables was in a favorable direction and the majority of the measures were significant at the .05 level. A global measure of life satisfaction "right now" changed between the pretest and posttest evaluations. However, significant differences of satisfaction compared to one year ago, other people their same age and sex, and their projection of satisfaction in the next 5 years did not change. Significant changes were also seen in participant negative affect, anxiety and depression. In total, the data collected over the 4-year period showed a number of important changes in a variety of mental health measures.

Transformative learning. In-depth interviews were conducted with 34 randomly selected participants on 10 openended questions to gather formative evaluation data and to assess transformative learning, the fourth objective (for full information on this portion of the cvaluation, see Christopher et al., 2001). Transformative learning is a concept that comes from adult education. Transformative Icarning occurs when learners reassess personal assumptions and examine whether their present approach to doing things is right for them (Clark, 1993; Courtenay, Merriam, \& Reeves, 1998; Sokol \& Cranton, 1998). This self-reflection helps learners prepare to take action. Programs that result in transformative learning create real life changes in participants; a conversion to a way of thinking about themselves and doing things that is "better" for them and their families.

Outcomes of transformative learning in the literature include (a) an empowered sense of self and an increase in self-confidence in new roles and relationships, (b) fundamental changes in the way learners see themselves and their life assumptions, (c) more functional strategies and resources for taking action and gaining control over their lives, (d) compassion for others, and (c) new connectedness with others (Courtenay, Merriam, \& Reeves, 1998; Taylor, 1997). Other less common outcomes include enhanced spirituality and an involvement in ways of knowing other than rational. These outcomes are fostered by (a) teachers who are empathetic, caring, authentic, sincere and demonstrate a high degree of integrity, (b) learning conditions that promote a sense of safety, openness, and trust, and (c) instructional methods that support a learner-centered approach that promotes student autonomy, participation, reflection, and collaboration (Robertson, 1996). 
Table 1. EDUFAIM Survey: Empowerment t-Test of Mean Change Scores $(N=162)$

Favorable

Direction

$n$

Change in Mean ${ }^{b}$

$S D$

$p$

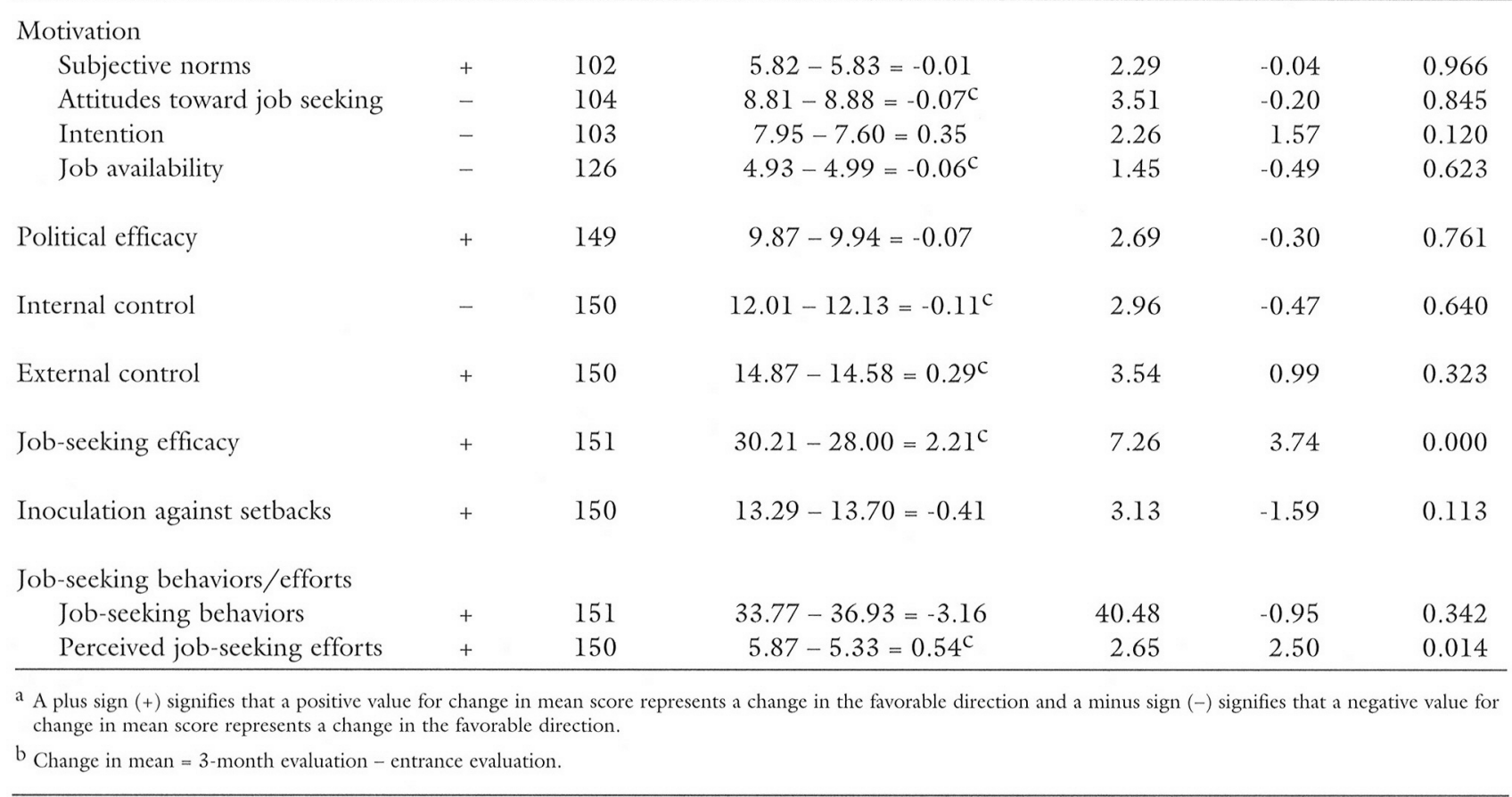

The 34 interviews were audiotaped and transcribed verbatim. NUD*IST qualitative software was used to analyze data (Sage, 1996). Analysis was based on methods described by Strauss and Corbin (1990), Patton (1987; 1990), and Bogdan and Bicklen (1992). All authors participated in the data analysis. Analysis revealed seven themes that cross-cut the 10 interview questions. The themes were labeled life skills, cmpowerment, social benefits, program value, facilitating learning, program weakness, and "just do it."

Responses subsumed under the life skills theme related to information and skills respondents learned in areas of money management, job readiness skills, parenting, and nutrition. The information and skills that respondents shared related directly to the content offered in four of the five core educational classes and reveal transformative learning outcomes. For instance, one participant remarked about changes in money management skills:

They belped me a lot on managing my money and paying my bills on time. I was behind on paying my rent a lot of the time. I bave gotten it to where I can make payments on it. My food bill has gotten a lot easier. Even at the end of the month I have groceries.

Responses under the empowerment theme related to changes respondents made in the way they saw themselves and in the way they interacted with the world. Issues under empowerment were separated into five areas: (a) empowcred to try skills they learned in class, (b) empowered to teach other people skills they learned, (c) a sense of selfrespect and hope, (d) feelings of confidence, and (c) taking better care of themselves. Respondents talked about changing their worldview due to participation in the program. Regarding changes in the area of self-respect and hope, one participant stated,

I respect myself more and bave more bope for the future. Because before I was always depressed and always mad. Now I have something to look forward to every week, because it is really hard to find jobs around here. They just keep my hopes up, before I was really depressed and now I bave more to look forward to.

One benefit of the program discussed by most clicnts was the social rewards they received from their involvement. Included under the theme social benefits were responses related to benefits received by participants that came from decreased isolation, getting to talk about issucs, being around other people with similar situations, and mecting new people and making friends, suggestive of transformative learning. For instance, one participant said, 
Table 2. EDUFAIM Survey: Mental Health t-Test of Mean Change Scores $(N=162)$

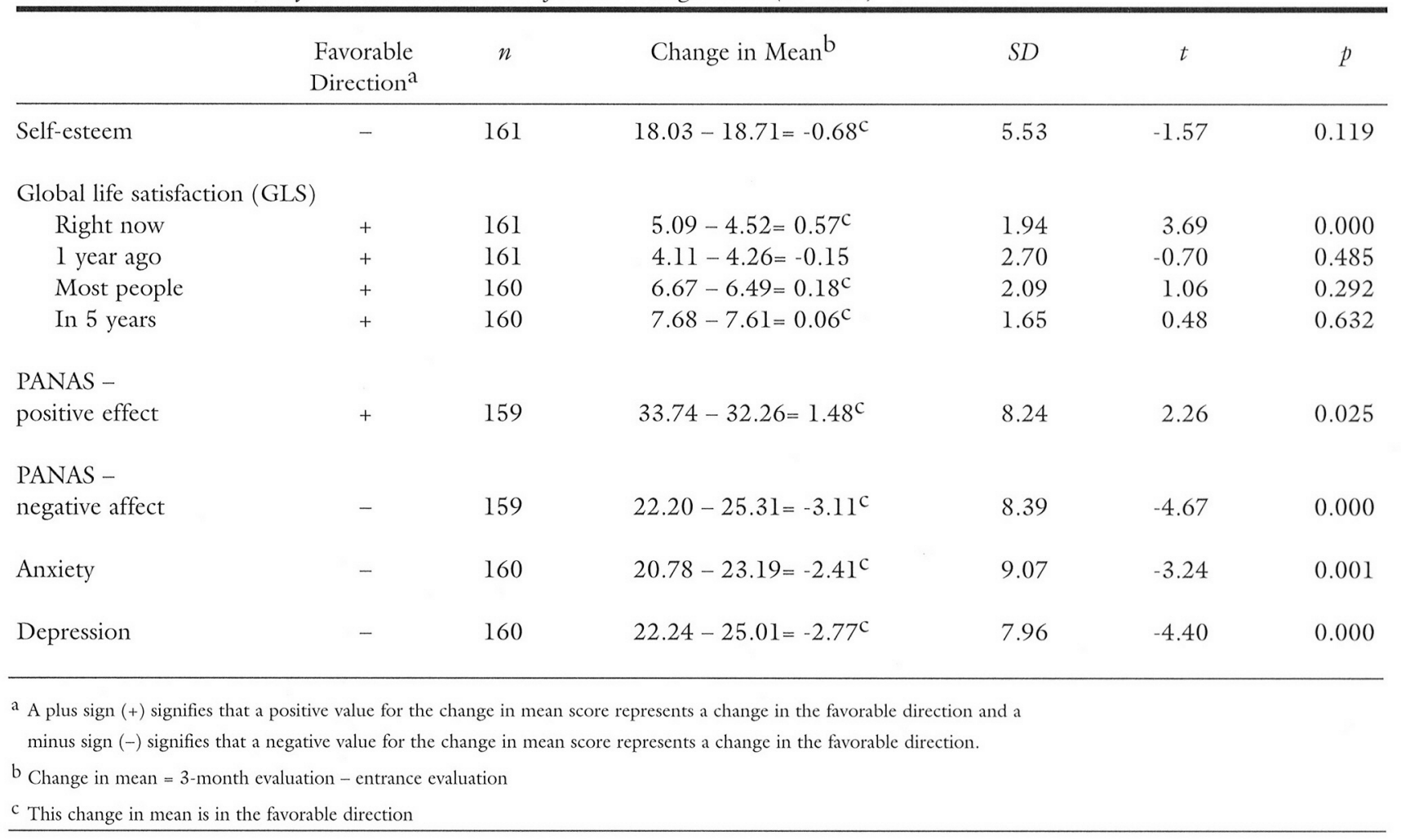

[Coming to EDUFAIM] wade life easier: I guess by making more friends. I don't feel so completely alone.

Under the theme program value, clients expressed general comments about the positive aspects of the program, many of which echo transformative learning outcomes. One client described the program value in this manner:

\section{It educates you for getting a job. How to belp your family out more, bow to take care of your family and yourself. It belps to educate, get an education. If you don't have an education it can help you get one by going for the GED. You can get the equivalency of the bigh school diploma if you don't have one, which will help get a better job later on.}

Under the theme of facilitating learning werc responses related to the content of the classes, the learning environment, instructors, and educational strategies used in educational sessions. The responses reported in this section were all positive. Ohe client who discussed the benefits of a positive learning environment said,

They [the instructors] make it fun and interesting to want to come here all the time. You sit there and listen to them and participate in what they are doing.
Comments related to rules and regulations, content dislikes, and the inconvenience of the program were included under program weaknesses. Most responses under the questions "What are some of the things you really don't like about the program" and "What about the EIDUFAIM program has made your life more difficult" were actually positive responses. A small minority the clients reported program weaknesses. One participant shared this example of program inconvenience: "Traveling the distances. I go 50 miles each time."

The "just do it" category came predominantly from responses to the question "If another person was about to enter the EDUFAIM program, what would you tell him or her?" Respondents made clear the benefit they derived from the program. The majority of the respondents made comments about getting as involved as the person can, taking advantage of what is offered, and using the information provided. One participant offered the following advice:

To go to the classes every week. Not to miss any cause if you do you miss out on something new, something different that could belp you out.

From our inductive analyses of participant responses, we concluded that EDUFAIM was fostering transformative learning. Narratives from participants demonstrated an 
empowcred sense of self, fundamental changes in self-perception, adoption of more functional approaches to life, and growth in other ways.

Cost containment. Under the fifth and final evaluation objective, an analysis of state welfare data supplicd by the Montana Department of Public Health and Human Services was conducted. Using data from the EDUFAIM sites between 1996-1999, a logistic regression was conducted to evaluate the impact of EDUFAIM affiliation (EDUFAIM participant vs. nonparticipant) on cost-related measures. The control variables used in the regression equation included gender, age, education and houschold size. The binary dependent variables (participants and nonparticipants) used in four separate regressions included, (a) any employment for 1998, (b) any earnings for 1998, (c) any unearned income for 1998, and(d) any food stamps for 1998 . Using an alpha level of .10, significantly less unearned income was seen with the EDUFAIM participants than the nonparticipants $(p=.04)$. No significant changes were seen with any employment for $1998(p=.25)$, any earnings for $1998(p=.12)$, or any food stamps for $1998(p=.98)$. However, the odds ratios generated through the regressions showed that the EDUFAIM participants had almost twice the probability of obtaining any employment in 1998 and more than twice the probability of generating any earnings in 1998. Therefore, the preliminary results are encouraging and merit additional investigations that incorporate larger sample sizes and additional data on EDUFAIM participants and nonparticipants throughout the state.

Multiple evaluation approaches. The deliberate use of multiple approaches to determine program effectiveness provided further evidence of EDUFAIM success. For example, the results identified through the 4-year analysis of changes in empowerment and mental health are supported by the results of the client interviews and the cost analysis. Specifically, the survey data showed significant changes in participant job-seeking efficacy and perceived job-seeking efforts. Similarly, the interviews showed that many participants had acquired important job readiness skills and a feeling of confidence for finding a job. Also, the cost analysis showed EDUFAIM participants had almost twice the probability of obtaining any employment in 1998 and more than twice the probability of generating any earnings than did non-participants. Collectively, these results show important changes in a host of job-related skills.

The second area that was supported through multiple measures was mental health. Significant changes in mental health measures were identified through 4-years of survey data related to life satisfaction, affect, anxiety and depression. These results were also supported by the results of the client interviews. Specifically, participants reported enhanced concepts of self (self-respect, self-confidence and self-esteem), less depression, and a sense of hope for the future. Therefore, these results converge and suggest positive changes in a number of influential measures of mental health and well-being.

\section{Effective Use of Evaluation Data}

An important part of EDUFAIM's success has been the timely and purposeful promotion of the program with key constituents at EDUFAIM sites and throughout the state. Local staff kept their legislators and community leaders aware of the program and how it was progressing by detailing the positive effect the program was having on participants. In addition, local EDUFAIM staff worked to make their communities aware of the program through news releases, meetings with legislators, commissioners, and collaborators, presentations to civic groups, telcvision news, and radio programs. Collaborating partners sent the good news about EDUFAIM around the state by word of mouth. In addition, we presented information about EDUFAIM at several statewide conferences to county welfare directors and others who might be instrumental in bringing EDUFAIM to their locale.

To further promote EDUFAIM, we produced a video titled "EDUFAIM: A Successful Program for Helping Montana Families Become Self-Supporting" and provided it to all county welfare directors and statewide agency heads (including the Governor), and to other key agencies and organizations where EDUFAIM staff play a role. This 17-minute video gives an overview of the EDUFAIM program and features clients telling their own stories of how EDUFAIM has shaped their lives. In addition, collaborating partners at EDUFAIM sites highlight the value of the program. Thus, participants and collaborators, not the sponsor, are the ones who actively "sell" the program to others. Evaluation data on the program are woven into the video. In addition, we developed a 4-page, popularized report about EDUFAIM. Within this report, we describe the EDUFAIM program, including stories from persons benefiting from the program. Statistical data were illustrated in simplified bar charts to give a visual representation of program results. This report serves as a stand-alone executive summary of the project and also as a companion to the video. The video and popularized report were shared in a variety of ways, such as one-on-one (e.g., informal lunches with stakeholders), during a formal open-house (c.g., we invited all of our stakeholders and facilitated a formal EDUFAIM presentation), and by targeted mail (e.g., a formal letter enclosed with the popularized report).

\section{Program Limitations}

It appears that EDUFAIM is successful in its goal to help empower persons toward self-support. The elements that have led to its success include effective collaborations, educational materials, teaching strategies, evaluation, and program promotion. While there is reason for optimism about the EDUFAIM program, there are also concerns about the program and the data which support its effectiveness. The first is its mandatory nature. Once persons elect to participate in EDUFAIM, they are required by the state welfare agency to complete the selected program offerings, or face 
sanctions. This fact is still an issue for at least some participants, although EDUFAIM staff strove to mediate this concern by developing personal connections with participants. The concern about sanctions might have altered responses to questions about the program. For example, during interviews about EDUFAIM, participants may have given socially desirable responses considering the perceived ramifications of criticizing a program partnered with a state agency that could impose economic sanctions. Steps were taken in the interview process so participants would not fear repercussions, so it is not felt that data were unduly affected.

A second concern was client attrition. Despite efforts made to follow-up on participants, provide clear deadlines, and offer cash incentives, we still faced major problems with client attrition. Thus, the positive findings attributed to EDUFAIM may be inflated by self-selection. To help reduce attrition in the future, it may be advisable to employ a person whose major role is data collection from each site. Such a remedy would have been too costly given the constraints of our grant funding. In the future the costs of such a person could be built into the funding structure for self-support programs.

Third, determining if the EDUFAIM program was responsible for participant's reported positive changes cannot be definitively answered by the research designs employed here. Posttest-only participant reports indicated that the knowledge and skills gained were directly related to EDUFAIM class content. However, these changes represent client perceptions of change and reported change versus direct observation of change. In addition, pretest-posttest mental health changes may have been due to other extraneous factors. Ideally, we would have addressed these concerns by using a quasi-experimental design that employed random assignment of participants to treatment and delayed intervention (control) groups. However, given the smaller sample size and the fact that delaying client participation in a program designed to empower persons toward self-support was not acceptable, we chose less rigorous designs with its recognized limitations.

A fourth limitation is that program effects were assessed at 3 months into their participation in the program. Whereas the evidence suggests transformative learning outcomes were seen, it may be difficult to believe that the complex changes associated with this type of learning could have occurred in this short time. It also is difficult to know how long the positive mental health changes and transformative learning outcomes may be maintained. Follow-up intervicws with participants would be ideal, an approach made more difficult given the highly transient nature of this population. Future research is contemplated for tracking and assessing participant life trajectories that could be associated with their participation in EDUFAIM.

Finally, this study reports impacts of EDUFAIM during the earliest stages of welfare reform, during the period of time when the number of clientele on public assistance roles took the steepest drop. While those most difficult to employ were among EDUFAIM participants, it is likely that the easiest-to-employ clientele are over-represented in this sample. Even for those who find work, the quality of employment opportunities lags behind reported increases in confidence and well-being among EDUFAIM participants. This factor, however, is beyond the scope of this program.

Despite these limitations, EDUFAIM proved to be an effective empowerment program for facilitating self-sufficient living based on the results of the 5-year intervention effort. We hope to see EDUFAIM expand to serve the needs of Montanans throughout the state and successful program components modeled throughout the nation.

\section{References}

Bogdan, R. C. \& Biklen, S. K. (1992). Qualitative restarch for cducation: An introduction to theory and methods. Boston: Allyn and Bacon.

Christopher, S., Dunnagan, T., Duncan, S. F., \& Paul, L. (2001). Education for self-support: Evaluating outcomes using transformative learning theory. Family Relations, 50, 134-142.

Clark, C. (1993). Transformational learning. In S. B. Merriam (Ed.), An update on adult learning. New directions for ad wlt leaning and continuing education, No. 57. San Francisco: Josscy-Bass.

Cochran, M., \& Woolever, F. (1983). Beyond the deficit model: The empowerment of parents with information and informal supports. In I. Sigcl \& L. Lagosa (Eds.), Changing familics (pp. 225-245). Ncw York: Plenum.

Cooperative Extension System. (1991). Reaching limited renowe auditnes. Washington, DC: Author:

Courtenay, B., Merriam, S. B., \& Reeves, P. (1998). 'The centrality of meaning- making in tranformational learning: How HIV-positive adults make sense of their lives. Adult Education Quartorly, 48(2).

Day, S. H. (1994). Life skills thaining moves women off welfare. The Reporter; $4,5,12-15$

Dunnagan, T., Duncan. S. F., \& Paul, L. (2000). Doing effective evaluations: A case study of family empowerment due to welfare teform. Evaluation and Program Planning, 23, 125-136.

Kirby, J. J. (1996, Winter). Welfare to work transition. Human Development and Family Life Bulletin, 1, 1-3, 5 .

Lee, T. R., \& Goddard, H. W. (1989). Developing family relationship skils to prevent substance abuse anong high-risk youth. Family Relations, 38, 301-305.

Minkler, M. (1997). Introduction and overview. In M. Minkler (Fd.), Community organizing and community luilding for berlth (pp. 3-19). New Brunswick, NJ: Rutgers University Press.

Patton, M. Q. (1987). How to use qualitative methods in epalaation. Newbury Park, CA: Sage.

Patton, M. Q. (1990). Qualitative evaluation and researcls mothods (2nd ed). Newbury Park, CA: Sage.

Robertson, D.L. (1996). Facilitating transformative learning: Attending to the dynamics of the educational helping relationship. Adult Education Quarterly, 47(1), 41-53.

Sage Publications Software. (1996). NUD*IST [Computer Software] Thousand Oaks, CA: Author:

Sokol, A., \& Cranton, P. (1998). Transforming, not training. Adult Learning, $9(3), 14-16$.

Strauss, A. \& Corbin, J. (1990). Basics of qualitative research: Grounded theory procedures and techniques. Newbury Park: Sage.

Taylor, E. (1997). Building upon the theoretical debate: A critical review of the empirical studies of Mezirow's transformative karning theory. Adult Education Quarterly, 48(1), 34-59. 
Montana QuickFacts. (1999). U. S. Census Bureau. Available: http://quickfacts.census.gov/gfd/states/30000.html

Vinokur, A., \& Caplan, R.D. (1987). Attitudes and social support: Determinants of job-secking behavior and well-being among the unemployed. Journal of Applied Social Psychology, 17 (12), 1007-1024.

Woods, B. (1998). Feedback on EDUFAIM: Montana's state strengthening project. Unpublished manuscript.

Zimmerman, M.A. (1990). Taking aim on empowerment research: On the distinction between individual and psychological conceptions. American Jounal of Community Psychology, 18 (1), 169-177
Stephen F. Duncan, PhD, is Professor of Family Life at Brigham Young University, School of Family Life, 350F SWKT, Provo, UT 84602. E-mail: sduncan@byu.edu. Tim Dunnagan, EdD, is associate professor, Suzanne Christopher, PhD, is associate professor, and Lynn Paul, EdD, is an extension Food and Nutrition specialist at Montana State University, Department of Health and Human Development, Bozeman, MT 59717.

Manuscript submitted: February 9, 2001

Revised: September 11, 2001

Accepted: October 31, 2001

Appendix 1. EDUFAIM Program Areas and Materials, Team Specialists, and Contact Information

Program Area and Materials

Nutrition And Health

Eating Right is Basic Program (3rd ed.) Lessons 1-16

Family Nutrition Program

Three Jeopardy games

Tickle Your Appetite

Individual and Family Development
(Milk Jeopardy, Fruit Jeopardy, Vegetable Jeopardy)

Contact Information

Team Specialists: Lynn Paul and Phyllis Dennee, Dept. of HHD, Montana State University, Bozeman, MT 59717. Tele.: 406-994-5702; Fax: 406-994-6314 E-mail: lpaul@montana.edu and pdennee@montana.edu

Michigan State University Extension, Tele.: 517-353-9102

Montana State University Extension, Tele.: 406-994-5702

Western Dairy Council, Tele.: 303-451-7711

(WIC/TEAM Nutrition Educator's Kit or Children) NFSMI, Tele.: 1-800-321-3054

Team Specialist: Stephen F. Duncan (former project leader), School of Family Life, 350F SWKT, Brigham Young University, Provo, UT 84602. Tele.: 801-422-1796; Fax: 801-422-0225. E-mail: sduncan@byu.edu

Charting a Positive Future for Teen Parents

Common Sense Parenting

University of Florida Extension. Tele.: 352-392-2411

Boys Town, Tele.: 1-800-282-6657

Empowerment Skills for Family Workers

FAIM Job Search Handbook

(Trainer's Guide and Participant Notebook)

Making Families Stronger

Parent Education Program (PEP)

Housing

Cornell Cooperative Extension, Tele.: 607-255-2237

Montana Department of Health and Human Services, Tele.: 406-444-5900 Montana State University Extension. Contact the developer, Tele.: 801-422-1796 Alabama Cooperative Extension, Tele.: 334-844-5690

Team Specialist: Mike Vogel, Dept. of Agriculture and Technology Education, Montana State University, Bozeman, MT 59717. Tele.: 406-994-3451;

Fax: 406-994-5417; E-mail: mvogel@montana.edu

A Clean and Healthy Home
EDUFAIM Training Materials, Housing and Home Environment
Healthy Indoor Air for America's Homes

Oregon State University Extension, Tele.: 541-737-2513

Montana State University Extension, Tele.: 406-994-3451

Team Specialist: Dave Sharpe, P.O Box 173580, Montana State University, Bozeman, MT 59717. Tele.: 406-994-2962; Fax: 406-994-5417; E-mail: dsharpe@montana.edu

From Job Seeker to Job Keeper

Resource Management

Center for Continuing Education, Yonkers Public Schools, Tele.: 914-376-8000

Team Specialist: Marsha Goetting, Dept. of Agricultural Economics and Economics, Montana State University, Bozeman, MT 59717. Tele.: 406-994-5695;

Fax: 406-994-4838; E-mail: goetting@montana.edu

Bucs

Cornell Cooperative Extension, Tele.: 607-255-2237

Getting More for Your Money

Managing Between Jobs

Planning to Stay Abead

University of Wisconsin Extension, Tele.: 608-262-3346

Individual Learning Packets: Setting Spending Priorities,

Ways to Track Expenses, Getting More From Your Money,

Credit Control, PowerPay, and Debt Free By??

Keys to Successful Money Management

Life Skills for Single Parents

Put Your Money To Work

Money Management Advisors

Money Matters

Take Control of Your Spending

Interdisciplinary

Balancing Work and Family

Planning Ahead, Staying Abead
Montana State University Extension, Tele.: 406-994-5695

Oklahoma State University Extension, Tele.:405-744-4065

North Dakota Extension, Tele.: 701-231-7882

Kentucky State University Cooperative Extension, Tele.: 502-597-6866

Washington State University Extension, Tele.:1-800-723-1763

University of Illinois Extension, Tele.: 217-333-5900

Iowa State University Extension, Tele.: 515-294-5247

Montana State University Extension, Tele.: 406-994-6745

University of New Hampshire Extension, Tele.: 603-862-2346 